\title{
Pain predicts overall survival in men with metastatic castration-resistant prostate cancer treated with radium-223
}

This article was published in the following Dove Medical Press journal:

OncoTargets and Therapy

\author{
Giandomenico Roviello' \\ Rosj Gallicchio ${ }^{2}$ \\ Giovanni Bozza' \\ Maria Grazia Rodriquenz' \\ Michele Aieta' \\ Giovanni Storto² \\ 'Division of Medical Oncology, \\ Department of Onco-Hematology, \\ IRCCS CROB, Referral Cancer \\ Center of Basilicata, 85028 Rionero in \\ Vulture, PZ, Italy; ${ }^{2}$ Nuclear Medicine \\ Department, IRCCS CROB, Referral \\ Cancer Center of Basilicata, 85028 \\ Rionero in Vulture, PZ, Italy
}

Background: Radium-223 dichloride is an alpha emitter approved for metastatic castrationresistant prostate cancer (mCRPC). Unfortunately, little data are available on the prognostic factors during radium-223-based therapy.

Patients and methods: Patients with histologically confirmed progressive CRPC with two or more bone metastases and symptomatic disease were eligible. Previous therapy with a novel hormonal therapy was allowed. The patients received six intravenous injections of radium-223 every 4 weeks. A visual analog scale (VAS) was adopted to evaluate patients' basal pain.

Results: A total of 25 patients were evaluated. Of these, $6(24 \%)$ reported VAS $<4$. After a median follow-up of 8 months, all patients died with a median overall survival of 8.3 months (95\% CI: 5.2-11.8 months), 12.6 months in the patients with VAS $<4$ vs 6.6 months in the patients with VAS $\geq 4(P=0.03)$.

Conclusion: The present study suggests that VAS could be prognostic of the survival of mCRPC treated with radium-223 irrespective of the limitations of a small number of patients and the retrospective nature of the data.

Keywords: radium-223, pain, prostate cancer, radioactive therapy

\section{Background}

Prostate cancer is one of the most frequently occurring solid tumors worldwide. ${ }^{1}$ Localized prostate cancer is generally treated with surgery or radiotherapy; unfortunately, in most patients, disease recurred with metastases overall in the bone sites. In fact, it was estimated that bone metastases are reported in $\sim 90 \%$ of metastatic prostate cancer cases. $^{2}$ In addition, bone metastases may be associated with significant morbidity and mortality (eg, pain, spinal fracture, and cord compression), impairing quality of life..$^{2-5}$ Therefore, different bone-targeted agents, including bisphosphonates and denosumab, have been developed. ${ }^{2-5}$ Radium-223 dichloride is an alpha emitter that is selectively incorporated in the bone matrix at sites of active mineralization via osteoblasts. ${ }^{6}$ In the ALSYMPCA (ALpharadin in SYMPtomatic Prostate CAncer) Phase III trial, radium-223 showed an overall survival (OS) benefit in patients with castration-resistant prostate cancer (CRPC) and symptomatic bone metastases. ${ }^{6}$ In 2013, radium-223 was approved by the US Food and Drug Administration (FDA) for the treatment of patients with CRPC, symptomatic bone metastases, and no known visceral metastatic disease. Unfortunately, little data are available on the predictive factors of response to radium-223based therapy. The visual analog scale (VAS) for pain is a unidimensional measurement of pain intensity that is widely used in medicine. ${ }^{7}$ Several reports have demonstrated
Correspondence: Giandomenico Roviello Division of Medical Oncology, Department of Onco-Hematology, IRCCS CROB, Referral Cancer Center of Basilicata, Via Padre Pio I, 85028 Rionero in Vulture, PZ, Italy

Email giandomenicoroviello@hotmail.it 
that pain is a statistically significant predictor of OS in men with metastatic CRPC. ${ }^{8,9}$ Therefore, the aim of this report is to verify whether the basal pain measured using the VAS for pain before radium-223-based therapy is related to its efficacy.

\section{Patients and methods Inclusion criteria}

This is a retrospective study of a cohort of patients treated with radium-223 in our single center enrollment. The patients were evaluated if they had histologically confirmed, progressive CRPC with two or more bone metastases detected by skeletal scintigraphy and no known visceral metastases. The presence of castration-resistant disease was defined as a serum testosterone level of $50 \mathrm{ng} / \mathrm{dL}$ or less $(\leq 2.0 \mathrm{nmol} / \mathrm{L})$ after bilateral orchiectomy or during treatment consisting of androgenablation therapy with a luteinizing hormone-releasing hormone agonist. Patients who had received docetaxel, abiraterone, or enzalutamide were enrolled. The patients were required to have symptomatic disease with the regular use of analgesic medication or treatment with external beam radiation therapy required for cancer-related bone pain within the previous 12 weeks. Additional eligibility criteria included evidence of progressively increasing prostate-specific antigen (PSA) values (two consecutive increases over the previous reference value) or radiographic evidence of disease progression, and adequate hematological, renal, and hepatic function. Additional exclusion criteria were previous hemibody external radiotherapy, the presence of visceral metastases, and imminent or established spinal cord compression. All patients provided written informed consent. This study was approved by the local ethics committee of the IRCCS CROB, Referral Cancer Center of Basilicata Hospital.

\section{Treatment plan and assessment}

The patients received six intravenous injections of radium223 (at a dose of $50 \mathrm{kBq} / \mathrm{kg}$ of body weight); each injection was administered every 4 weeks. Safety was evaluated on day 15 of cycle 1 and on day 1 of each subsequent cycle. Laboratory tests, red blood cell, white blood cell, and platelet counts, and a comprehensive screening were performed at baseline. Efficacy assessments included survival status, clinically evaluated symptomatic skeletal events, and total ALP and PSA concentrations. Radiological investigations included chest, abdominal, and pelvic CT or MRI and bone scans at basal and at the end of six injections and after every 3 months or sooner if clinically indicated.

\section{Statistical analysis}

VAS was recorded at the time of initiation and at the end of radium-223 treatment. The primary end point of this retrospective study was OS, defined as the time from the initiation of radium-223 to the date of death, regardless of cause. Secondary end points included the percentage of patients with an ALP reduction $>30 \%$ from the basal value and the radiological response as evaluated according to Response Evaluation Criteria In Solid Tumors 1.1 criteria. Differences in the categorized variables were assessed using Fisher's exact test. For the continuous variables, Student's $t$-test or Mann-Whitney $U$ tests were used to compare the groups. Kaplan-Meier survival curves were calculated and compared using the log-rank test. $P$-values $<0.05$ were considered to indicate statistical significance. All analyses were conducted using Stata software.

\section{Results}

From November 2014 through March 2017, a total of 25 patients were treated with radium-223. Of these, 6 (24\%) reported VAS $<4$ at baseline evaluation. Among these, none had a total ALP $>220 \mathrm{U} / \mathrm{L}$. In addition, none used opioids and this subgroup had less metastatic tumor burden as shown by the extent of disease and the number of metastatic sites. A total of 17 (68\%) of the 25 patients received all six injections of radium-223. The median number of injections was six for the subgroup with VAS $<4$ and five for the others. Baseline clinical characteristics of all of the men are reported in Table 1. After a median follow-up of 8 months, all of the patients died. They had a median OS of 8.3 months $(95 \%$ CI: 5.2-11.8 months), 12.6 months in patients with VAS $<4$ vs 6.6 months in those with $\operatorname{VAS} \geq 4(P=0.03$; Figure 1$)$. In addition, data on the secondary end points are reported in Table 2. After adjusting for clinical covariates (total ALP level, Eastern Cooperative Oncology Group performance status, lines of therapies, and extent of disease), VAS $<4$ remained a prognostic factor of survival $(\mathrm{HR}=0.32,95 \%$ CI: $0.20-0.95, P=0.04)$. Finally, data on basal VAS and its modification after radium-223 are shown in Figure 2.

\section{Discussion}

The randomized ALSYMPCA Phase III trial compared radium-223 efficacy vs placebo in patients with CRPC and symptomatic bone metastases. ${ }^{6}$ This study included only patients with disease progression during docetaxel treatment or those who were unfit to receive chemotherapy (43\% of the enrolled men). In the updated analysis, the median OS was 14.9 months in the radium-223 group and 11.3 months in the placebo group. In our study, we observed a median OS of 8.3 months for radium-223, which was lower than that observed in the ALSYMPCA study. However, we also included patients with disease progression during other 
Table I Baseline characteristics of the patients

\begin{tabular}{|c|c|c|c|}
\hline & $\begin{array}{l}\text { All patients } \\
\mathbf{N}=\mathbf{2 5}\end{array}$ & $\begin{array}{l}\text { VAS }<4 \\
\mathbf{N}=6\end{array}$ & $\begin{array}{l}\text { VAS } \geq 4 \\
N=19\end{array}$ \\
\hline \multicolumn{4}{|l|}{ Age } \\
\hline Median (range) [year] & $78(58-88)$ & $76(64-80)$ & $78(58-88)$ \\
\hline \multicolumn{4}{|l|}{ Total ALP [no (\%)] } \\
\hline$<220 \mathrm{U} / \mathrm{L}$ & $12(48 \%)$ & $6(100 \%)$ & $6(31.5 \%)$ \\
\hline$\geq 220 \mathrm{U} / \mathrm{L}$ & $13(42 \%)$ & 0 & $13(68.4 \%)$ \\
\hline \multicolumn{4}{|l|}{ Gleason score } \\
\hline$<8$ & $12(48 \%)$ & $2(33.3 \%)$ & $10(55.5 \%)$ \\
\hline$\geq 8$ & $12(48 \%)$ & $4(66.7 \%)$ & $8(42.1 \%)$ \\
\hline \multicolumn{4}{|l|}{ Lines of therapy } \\
\hline 1 & $20(80 \%)$ & $6(100 \%)$ & $14(73.7 \%)$ \\
\hline 2 & $17(68 \%)$ & $5(83.3 \%)$ & $12(63.1 \%)$ \\
\hline 3 & $9(36 \%)$ & $3(50 \%)$ & $6(31.5 \%)$ \\
\hline 4 & $6(24 \%)$ & $2(33.3 \%)$ & $4(21 \%)$ \\
\hline \multicolumn{4}{|l|}{ Kind of drugs [no (\%)] } \\
\hline Docetaxel & $17(68 \%)$ & $4(66.7 \%)$ & $13(68.4 \%)$ \\
\hline Novel hormonal therapy & $16(64 \%)$ & $2(33.3 \%)$ & $14(77.7 \%)$ \\
\hline Cabazitaxel & $8(32 \%)$ & $2(33.3 \%)$ & $6(31.5 \%)$ \\
\hline Other & $7(28 \%)$ & I (I6.7\%) & $6(31.5 \%)$ \\
\hline \multicolumn{4}{|c|}{ ECOG performance status score [no (\%)] } \\
\hline$\leq 2$ & $22(88 \%)$ & $6(100 \%)$ & $16(84.3 \%)$ \\
\hline$>2$ & $3(12 \%)$ & 0 & $3(15.7 \%)$ \\
\hline VAS for pain (median) & 5 & 2 & 6 \\
\hline \multicolumn{4}{|l|}{ Pain therapy } \\
\hline No opioid use & $14(56 \%)$ & $6(100 \%)$ & $8(42.1 \%)$ \\
\hline Opioid use & II (44\%) & 0 & II (57.9\%) \\
\hline \multicolumn{4}{|l|}{ Extent of disease [no (\%)] } \\
\hline$<6$ metastases & $\mathrm{I}(4 \%)$ & 0 & $\mathrm{I}(5.3 \%)$ \\
\hline 6-20 metastases & $15(60 \%)$ & $4(66.7 \%)$ & II (57.9\%) \\
\hline$>20$ metastases & $8(32 \%)$ & $2(33.3 \%)$ & $6(31.5 \%)$ \\
\hline Superscan & $\mathrm{I}(4 \%)$ & 0 & $\mathrm{I}(5.3 \%)$ \\
\hline \multicolumn{4}{|c|}{ External beam radiation therapy within 12 weeks [no (\%)] } \\
\hline Yes & $4(16 \%)$ & I (I6.7\%) & $3(15.7 \%)$ \\
\hline No & $21(84 \%)$ & $5(83.3 \%)$ & $16(84.3 \%)$ \\
\hline \multicolumn{4}{|l|}{ Bone-targeted agents [no (\%)] } \\
\hline Yes & $4(16 \%)$ & $\mathrm{I}(16.7 \%)$ & $3(15.7 \%)$ \\
\hline No & $21(84 \%)$ & $5(83.3 \%)$ & $16(84.3 \%)$ \\
\hline \multicolumn{4}{|l|}{ Median biochemical values (range) } \\
\hline Hemoglobin $(\mathrm{g} / \mathrm{dL})$ & 12 & 13.3 & 10.6 \\
\hline Albumin $(g / L)$ & 40 & 43 & 39 \\
\hline Lactate dehydrogenase (U/L) & 315 & 290 & 320 \\
\hline PSA $(\mu g / L)$ & $79.9(9-4,560)$ & $30.3(9-80)$ & $123(7.6-4,560)$ \\
\hline Median injection of radium-223 & 6 & 6 & 5 \\
\hline
\end{tabular}

Abbreviations: ECOG, Eastern Cooperative Oncology Group; PSA, prostate-specific antigen; VAS, visual analog scale.

approved drugs such as abiraterone acetate, enzalutamide, and cabazitaxel, with $24 \%$ of the men treated with four lines of therapy. These data may reflect a more aggressive disease and explain the lower OS of our patients. Interestingly, we observed a statistically significant advantage in OS for patients with VAS $<4$ compared to other patients (12.6 vs 6.6 months), in particular, in the group of VAS $<4$, the OS was quite similar to that of the ALSYMPCA study. Even if 


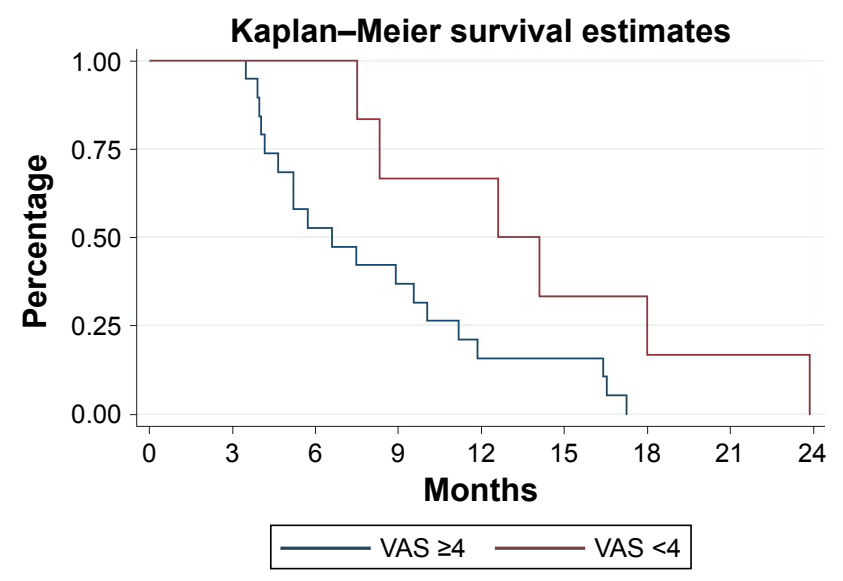

Figure I Estimated OS for metastatic CRPC patients with VAS $<4$ (red) and with VAS $\geq 4$ (blue).

Abbreviations: CRPC, castration-resistant prostate cancer; OS, overall survival; VAS, visual analog scale.

pain is a multifactorial parameter, there is a strict correlation with tumor burden on one side and with survival on the other. In addition, pain is a statistically significant predictor of OS in men with metastatic CRPC with bone metastases. ${ }^{8}$ In fact, men with minimal symptoms have prolonged survival. ${ }^{9}$ These data were all confirmed in the men treated with radium-223.

Although radium-223 is approved by the FDA in 2013, studies with high levels of evidence on the optimal sequence of its administration among all other approved treatments for CRPC are lacking. In addition, the ALSYMPCA study had a main limitation of the absence of patients previously or concomitantly treated with new hormonal therapies, such as abiraterone or enzalutamide. Recently, a single-arm Phase III-b trial conducted to enable early access to radium-223 included patients concomitantly treated with a novel hormonal therapy. ${ }^{10}$ It showed results quite similar to those of

Table 2 Secondary end points

\begin{tabular}{|c|c|c|c|c|}
\hline & $\begin{array}{l}\text { All } \\
\text { patients } \\
\mathbf{N}=\mathbf{2 5}\end{array}$ & $\begin{array}{l}\text { VAS }<4 \\
\mathbf{N}=6\end{array}$ & $\begin{array}{l}\text { VAS } \geq 4 \\
N=19\end{array}$ & $P$-value \\
\hline ALP rr $>30 \%$ & $9(36 \%)$ & $2(33.3 \%)$ & $7(36.8 \%)$ & 0.6 \\
\hline \multicolumn{5}{|c|}{ Radiological response } \\
\hline SD & $12(48 \%)$ & $2(33.3 \%)$ & $10(52.6 \%)$ & \multirow[t]{2}{*}{0.3} \\
\hline PD & 13 (52\%) & $4(66.7 \%)$ & 9 (47.4\%) & \\
\hline \multicolumn{5}{|l|}{ Pre-radium-223 } \\
\hline $\begin{array}{l}\text { Analog scale } \\
\text { for pain (VAS } \\
\text { pain; median) }\end{array}$ & 5 & 2 & 6 & \\
\hline \multicolumn{5}{|l|}{ Post-radium-223 } \\
\hline $\begin{array}{l}\text { Analog scale } \\
\text { for pain (VAS } \\
\text { pain; median) }\end{array}$ & 3 & 1.5 & 3 & \\
\hline
\end{tabular}

Abbreviations: PD, progressive disease; rr, response rate; SD, stable disease; VAS, visual analog scale.

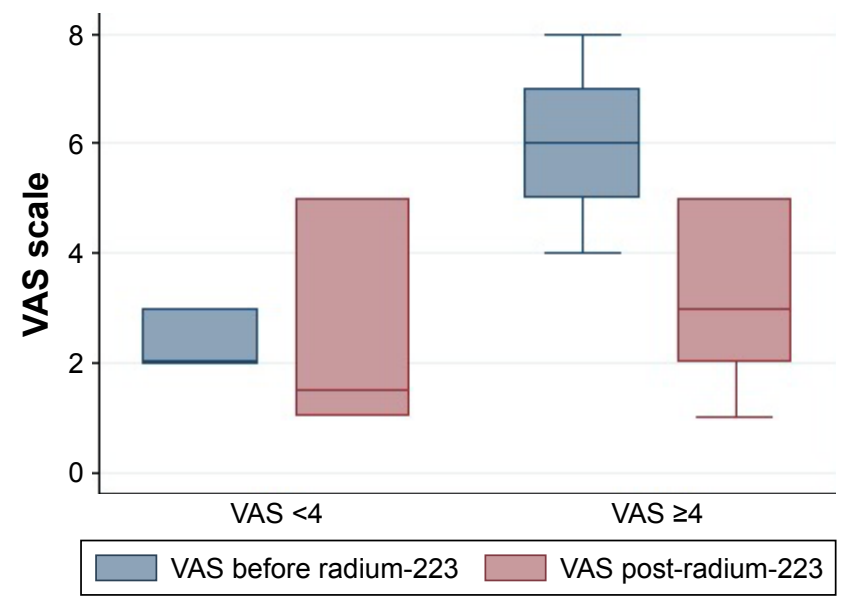

Figure 2 Median VAS before and post-radium-223 according to initial VAS. Abbreviation: VAS, visual analog scale.

the ALSYMPCA trial, with a longer OS in patients concomitantly treated with a novel hormonal therapy compared to those without. However, the European Medicines Agency announced at the Pharmacovigilance Risk Assessment Committee meeting conducted from 27 to 30 November, 2017 , that there was an increased risk of death and fractures reported in an ongoing clinical trial of prostate cancer medicine on comparing radium-223 with placebo, both administered in combination with abiraterone acetate and prednisone/prednisolone. ${ }^{11}$

\section{Conclusion}

The present study suggests a possible effect of radium-223 on the OS of CRPC with VAS $<4$ and also in heavily pretreated patients for whom data are lacking. Unfortunately, the present study had several limitations, including a small number of evaluated patients and the retrospective nature of the data. Therefore, prospective large-scale trials are necessary to evaluate the role of radium-223 in the sequence of treatment of metastatic CRPC.

\section{Disclosure}

The authors report no conflicts of interest in this work.

\section{References}

1. Wong MC, Goggins WB, Wang HH, et al. Global incidence and mortality for prostate cancer: analysis of temporal patterns and trends in 36 countries. Eur Urol. 2016;70(5):862-874.

2. Zustovich F, Fabiani F. Therapeutic opportunities for castration-resistant prostate cancer patients with bone metastases. Crit Rev Oncol Hematol. 2014;91(2):197-209.

3. Saad ED, Buyse M. Overall survival: patient outcome, therapeutic objective, clinical trial end point, or public health measure? J Clin Oncol. 2012;30(15):1750-1754.

4. Rajpar S, Fizazi K. Bone targeted therapies in metastatic castrationresistant prostate cancer. Cancer J. 2013;19(1):66-70. 
5. Sathiakumar N, Delzell E, Morrisey MA, et al. Mortality following bone metastasis and skeletal-related events among men with prostate cancer: a population-based analysis of US Medicare beneficiaries, 1999-2006. Prostate Cancer Prostatic Dis. 2011;14(2):177-183.

6. Parker C, Nilsson S, Heinrich D, et al. Alpha emitter radium-223 and survival in metastatic prostate cancer. $N$ Engl J Med. 2013;369(3): 213-223.

7. Mccormack HM, Horne DJ, Sheather S. Clinical applications of visual analogue scales: a critical review. Psychol Med. 1988;18(4): 1007-1019.

8. Halabi S, Vogelzang NJ, Kornblith AB, et al. Pain predicts overall survival in men with metastatic castration-refractory prostate cancer. J Clin Oncol. 2008;26(15):2544-2549.
9. Berthold DR, Pond GR, Roessner M, de Wit R, Eisenberger M, Tannock AI; TAX-327 investigators. Treatment of hormone-refractory prostate cancer with docetaxel or mitoxantrone: relationships between prostate-specific antigen, pain, and quality of life response and survival in the TAX-327 study. Clin Cancer Res. 2008;14(9):2763-2767.

10. Saad F, Carles J, Gillessen S, et al. Radium-223 and concomitant therapies in patients with metastatic castration-resistant prostate cancer: an international, early access, open-label, single-arm phase $3 \mathrm{~b}$ trial. Lancet Oncol. 2016;17(9):1306-1316.

11. Sartor O, Sharma D. Radium and other alpha emitters in prostate cancer. Transl Androl Urol. 2018;7(3):436-444.

\section{Publish your work in this journal}

OncoTargets and Therapy is an international, peer-reviewed, open access journal focusing on the pathological basis of all cancers, potential targets for therapy and treatment protocols employed to improve the management of cancer patients. The journal also focuses on the impact of management programs and new therapeutic agents and protocols on

\section{Dovepress}

patient perspectives such as quality of life, adherence and satisfaction. The manuscript management system is completely online and includes a very quick and fair peer-review system, which is all easy to use. Visit http://www.dovepress.com/testimonials.php to read real quotes from published authors.

Submit your manuscript here: http://www.dovepress.com/oncotargets-and-therapy-journal 